\title{
Take the Plunge: A Plea for, and Advice on, Entering University Administration*
}

\author{
Herbert Waltzer, Miami University
}

$M$ y plea to "take the plunge," "throw their hats into the ring," and accept university and college administrative posts is directed to able and energetic political scientists, especially (or initially) at their home institutions and for limited tours of duty. The plea is made with urgency because of my observation and unhappy conclusion that in recent years too many in the national pool of those who seek and hold central administrative offices are far from first-rate. Scanning the scene and reading the news of higher education leadership and management, I am not heartened that strong and steady hands are at the helm of the academy. Far too many administrators, for example, have their eyes not on the interests and future of the university or college they ostensibly serve but on the next job up the ladder or at a larger or more prestigious institution.

The advice I offer is a realistic but optimistic assessment of life as an academic administrator. It is based on my own varied experiences in faculty and administrative leadership positions and liberated by my recent retirement. Over the following pages, I explore the elements, opportunities and problems, and challenges and chores of administrative positions, and I suggest what prospective administrators should ask for and expect when accepting administrative appointments. While the advice is straightforward and unvarnished, and addresses the downsides as well as the upsides of holding administrative posts, I offer it in the

Herbert Waltzer is professor emeritus of political science at Miami University. He served several tours in university administration as an academic officer, consultant, and troubleshooter at Miami, and also as a trainer of administrators for and consultant to the Ohio Board of Regents, higher education associations, and many universities and colleges. His doctorate is from New York University. hopes of motivating more highly competent and experienced teacherscholars of politics to consider taking tours of duty in academic administration. In many ways, the analog for administrative tasks is scholarship. They both involve bringing others, be they colleagues, students, or other constituents or publics, to understand a complex phenomenon by framing questions so that the core issues are clear to all and that a reasonable and empirically-grounded answer or policy can be found and then implemented by common effort.

Now that you have some sense of what I'm going on about, should you read the entire article? Answer for yourself the following questions.

- Do you think that you would find satisfaction in shaping academic institutions and policy? in leading and moving colleagues to define and achieve goals and to direct, as required by the times, institutional preservation or change? in problem identification and management? in troubleshooting? in, to state it in pragmatic political terms, "wheeling and dealing?"

- Do you have both the compassion and the starch to tolerate the daily doses of human diversity and perversity you will have to ingest, and to know when empathy and accommodation are appropriate and when institutional interests must prevail, however hard-hearted pursuing priorities may make you appear?

- Do you think you could find satisfaction or, better yet, gratification in supporting the academic work of colleagues and applauding and rewarding their accomplishments?

- Do you have the sense of humor needed to deal with the foibles and follies of others (and yourself), the self-confidence not to take yourself and your position too seriously, and the toughness to make decisions that colleagues will not like?

- Do you have the sense that you would do administrative tasks easily and naturally, and be as good at doing them as you are at talking about and studying them?

- Would you enjoy making the organization run and run well?

If you answered more than one of the questions affirmatively, you should seriously consider serving a stint in academic administration and you should also read this article.

\section{The Experience}

Entering central administration can be a growth opportunity and an eye-opening experience for political scientists. It can also be fun and rewarding for those who enjoy problem solving, trouble shooting, doing politics, and managing people.

Administrative problem solving involves parsing and managing problems by finding better ways to cope with them. Similarly, trouble shooting requires administrators to put out fires started by others. On rarer occasions, it also calls on one to prevent fires.

For administrators, doing politics means matching political wits and skills with others, testing one's mettle by getting off the sidelines and into the game, and earning, thereby, the faculty privilege of criticizing the administrative performances of others and not only spouting your views as to how it should be done but also demonstrating how it can be done.

Lastly, testing and demonstrating your skills at managing people and conflict entails weighing and balancing conflicting values and interests 
and bringing people to accommodation and agreement. A good academic manager defines goals for the institution and achieves them by developing, winning support for, and implementing sound academic policies. Central administrative posts offer tough, multidimensional, and demanding tests of oneself, and they are to be embraced not avoided.

\section{The Issues and the Challenges}

I quickly learned, sometimes the hard way, that being an administrator is very different from being a faculty member. As an administrator, I had to understand and work to improve institutional mission, academic degree programs and their requirements and curricula, student life, cocurricular and extracurricular programs and activities, finance and business affairs, relations with parents, alumni/ae, and the public, and federal, state and community politics and policy in ways I never did as a full-time professor. As unlikely as some may consider it to be, the expanded perspective and responsibilities are a distinct benefit of being in central administration.

For political scientists, holding administrative office offers unique opportunities to practice what we preach, to see how good we are at political management, and to test the theories of the discipline (including one's favorites) in the microcosmic polity that is the university or college. The scale is smaller than state or global organizations, but since the elements of the polity are present in the university it can serve as a real-life laboratory for a postdoctoral practicum in politics. Political scientists should serve in academic administration because, as political scientists, they should be good at it. Moreover, it offers one the important opportunity, during or after completing a tour of duty, to reflect on and write about the politics of higher education and leadership and management. Political scientists should not leave that field of inquiry exclusively to those in the discipline of higher education administration.

\section{The Terms of Negotiation}

You should carefully and forcefully negotiate the terms of your appointment so that you can maintain your scholarly bona fides while in administration. You should continue to teach at least one course each year (or more if possible!), do the basic reading required to maintain currency in your field, engage in at least some research with product, and maintain some presence in your academic department and the discipline. It is unlikely that you will be at a stage in your career when lack of extensive publishing will result in your perishing, but maintaining some basic continuity in research and publication, as well as in teaching, will serve as a tonic while in an administrative post. Doing so will also establish you as an exemplar to others in the faculty and administration, and it will be crucial in enhancing your authority and your career flexibility.

Under no circumstance should you surrender your departmental office! Some may argue otherwise and there may be plaintive cries of space shortages, but I am convinced that it is important to keep one's office and to spend some scheduled time there every week. You want to avoid the situation, discussed later, in which you become so removed from your department and the discipline that return is foreclosed to you and you have no alternative but to remain in administration. For example, if it is your practice to take lunch with faculty colleagues, continue to do so as your schedule permits. Attend at least some department meetings while in your administrative post, but be sure to check the agenda with your department chair to ensure the appropriateness of your presence. You must also take pains to exercise the ap- propriate tact so as not to be intrusive and not to reveal as-yet-unannounced administrative decisions and actions to which you are privy; you must be careful not to be inappropriately "used" by departmental colleagues. After all, you have an interest and a stake in the future of your departmental home because, presumably, you will be returning to it.

Can this be done? Can you fulfill the duties of a central administrative position and also maintain your disciplinary connections? Based upon my experiences and those of others with whom I have worked, the answer is absolutely "Yes." The terms need to be negotiated up front so that there are no surprises, and it will take extra effort, but it can and must be done. Otherwise, the administrative job may (will!) become enervating, and you will find it increasingly difficult to return to professoring. Indeed, every faculty member knows able people locked in administrative posts they would like to vacate but cannot because they have lost touch with their discipline and cannot confidently or effectively return to the teacherscholar role.

The counsel offered is to accept administrative posts for a term (or perhaps two) and then to return to your department. Additional administrative assignments should only be accepted on a noncontinuous basis. I realize this advice begs the question of whether someone can be effective, have an impact, and make a difference in a limited tour in an administrative post. Yes, if you enter the post with the objectives of learning the office quickly by talking with staff and others and reading reports and other documents, deciding what needs to be done, putting the tasks in priority order and selecting a manageable number for attention, and setting timetables that border on impatience but can be met within your anticipated tenure in office. After all, if you are on your home turf, then you have served as a faculty member and on committees for some time and "know" the job, the culture, people, terrain and problems of the institution and the office, and what you can achieve with your 
energy and skills and the other resources you can muster. If you tell your superior of your goals and plans and the resources you need, you will be likely to get many of those resources.

\section{Be Prepared! Advisories on Life in Academic Administration}

What follows is a cautionary discussion of some of the less appealing aspects of university and college administration. My aim is to encourage you to pursue administrative opportunities with your eyes open to the less attractive aspects of the culture of academic administration, and to offer advice on how to respond to them.

\section{Term Limits}

Accept administrative posts for limited tenure, set goals for each term and work hard to achieve them, and then to return to your faculty position without foreclosing the option of returning to administration at a later date. Why? Because if you remain in administration for several terms ("too long"), you will find yourself bored with the bureaucratic tedia, aggravated by the glacial pace, and, as a teacherscholar, missing the intellectual stimulation of the classroom, research and writing, and departmental and disciplinary colleagues. The call to administration may come again, but the intervening return to the faculty will be rejuvenating, pleasurable, and productive, and it will prepare you for handling later challenges in administration.

\section{Trust: The Coin of the Realm}

Trust is a critical asset for all members of a university community. As an administrator, you will be in the loop of institutional and personal news and gossip. If people tell you something in confidence, even if the subject is being bandied about by others, you must keep the information to yourself. Keep the confidence and, thereby, keep the respect and confidence of others that you are a person of talent and integ- rity-a person to be trusted. In my case, the person who was the angriest with me for following this rule was my wife. Why? Because when people told me things in confidence, even if I knew that they had told it to others with the same admonition that they really did not expect to be honored, I fully kept that confidence by not repeating it to others, including my wife. She often found herself the last to learn of others' follies and foibles with the information coming not from me but from other university spouses and acquaintances, usually when such stories were table talk at dinner parties we attended. Too many times, I looked across the table only to see the "Once-again-I-am-the-last-to-knowand-we-will-discuss-this-later" look. I would innocently shrug my shoulders and look unavailingly to heaven for protection. While I may not have been the most communicative spouse, my reputation for integrity was intact (with everyone but my wife, of course). I do not say this as a boast. The high trust people placed in my discretion played an important role in advancing my career. It will do the same for you.

The Two Faces of the University: Mutually Unflattering Images

The most troubling (indeed the ugliest) truth I leaned as a facultymember-turned-administrator-andconsultant is that the faculty and the administration have almost irredeemably negative opinions of each other. I have witnessed first hand, and from both sides, the unpleasantness and dysfunctional disharmony this creates, and can also testify to the distances from reality of these perceptions. Be alert to this! Those who hold administrative offices in universities and colleges are not as incompetent and malevolent as faculty think they are, but neither are they as competent and noble as they think themselves to be. Administrators are not as lazy, unproductive and irrelevant to the academic enterprise as faculty think they are, nor are administrators as hard working, contributing, and essential as they think they are. In reality, many administrators are able, dedicated, and hard-working; others are dull, uninterested, and barely working. But then again, to be honest, the same could be said about faculty members.

Faculty tend to assume that most of what goes on in central administration has only a marginal direct effect on the primary day-to-day business of the institution of higher learning, that what administrators do has little relevance to or influence over what goes on in the classroom and in the laboratory. In truth, what goes on in the administration structures in important, supportive or unsupportive, ways the institution's environment and the work of the faculty.

Upon first entering administration, a faculty member may find it difficult to deal with long-time administrators' generally negative, and sometimes outright defamatory, heartfelt and too-often-aired views about faculty. Even though central administrators regularly invoke faculty as "the heart of the institution" for public and political consumption, or as therapy for faculty egos, or to soften the faculty for less than desirable raises, many administratorsacademic and especially nonacademic and high ranking but especially low-do not have or voice positive opinions of faculty members. They see faculty as privileged, overpaid, underworked, pampered, whiny, and weird.

Understanding why administrators hold faculty in such low esteem will help you to confront and combat this unfortunate, unpleasant, and destructive stereotype. First, faculty members see the university exclusively in academic terms. The very nature of an administrative post, on the other hand, requires its occupant to develop a view and vision broader than that of a faculty member. Of necessity, central administrators must deal with student life and expectations, intercollegiate and recreational sports, cocurricular and extracurricular programs, residence and dining halls, campus security, town/gown relations, and a host of other elements of university life. As a result, central administrators quickly come to consider faculty as no more than another (un)organized 
interest with a set of unreasonable demands and expectations, the most unreasonable of which is that its demands have primacy over those of other constituencies

and the common-

weal. Administra-

tors have to deal

with the interests and expectations of the faculty and also of undergraduate students, graduate students, student athletes and their team coaches, alumni/ae, parents, staff, governing boards and bodies, public authorities, politicians who use the university as fodder for their political ambitions,

When accepting administrative posts, you must take the measure of those you will work for and with, listen to their words but also judge their underlying characters, and then determine the parameters of your own behavior. and the general public. To say the least, administrators answer to a complicated mix of constituencies and must perform a daunting but exhilarating juggling act.

Second, administrators spend a large part-indeed an incredibly large part-of their time and energy dealing with a small number of exceptionally bad actors among the faculty. Faculty do not have any sense of the range of unprofessional, unethical, criminal, rude, arrogant, and just plain stupid behaviors of a few of their colleagues, or any appreciation for the hours administrators must spend and the agonies they must endure dealing with these "bad apples" and the messes they create. If they knew, they would just hang their heads in disbelief and despair, and they.would better appreciate those in their administrations.

Third, administrators too often are academics who sought their posts because they discovered belatedly that they did not enjoy or were not good at what faculty do: teach and research. Too often, to steal a phrase, those who can't teach and do research administer those who can and do. Other administrators may have been perfectly competent and content professors but have not kept up their academic credentials. As a result, they envy faculty while they remain unhappily tied to an administrative job they no longer find attractive but which they cannot leave. What are needed, of course, are university administrators who have demonstrated that they can do it all well-teach, do research, and manage the institution.

Finally, faculty scare the hell out of at least some administrators. Faculty members required to clear the high hurdles of their doctorates, meet the rigorous if not cruel requirements for tenure and promotion, have their scholarly work peer reviewed, and stand in front of classes of demanding but not always assiduous or attentive students (who later evaluate them) and in front of other publics could not be incompetent, shy, or voiceless. Faculty members are smart, determined if not dogged, can think on their feet, are articulate if not wordy, are persuasive, and they can be intimidating.

Because they harbor unflattering and hostile images of each other, administrators and faculty often lack a shared sense of community in the institution, which makes ensuring the smooth functioning of an institution difficult. Sometimes, you will find it hard to hold your tongue and not respond to attacks on you and your faculty colleagues. While it is sometimes appropriate as well as cathartic to give what you get, these times are rare and it is almost always better to take the high road when answering critics.

\section{Face Time}

Administrators envy faculty members their opportunities to come and go as they please. In contrast, administrators, who function in a more bureaucratized environment, have to put in "face time" at the office and work during academic breaks. In terms of being able to control their work schedules, faculty are privileged in ways few other professionals are.

As an administrator, you will be expected to be in your office, "doing administration," and available to anyone who seeks you during the workday. Indeed, it is not acceptable or de rigueur to sit at your administrator's desk reading a disciplinary book or journal, doing scholarly research and writing, or preparing for a class. You are supposed to be administrating! Frightening, isn't this? At a minimum, most new administrators will find this circumscription of their time disconcerting, nervewracking, debilitating, boring, and wasteful.

Don't be discouraged! You do not have to surrender to this perceived requirement. I didn't. In available time, whether in my administrative or departmental office, I prepared for classes, reviewed dissertation manuscripts and conducted tutorials, read in my field, and did some research and writing. The key is to negotiate the terms of your appointment to ensure that you do not fall victim to a custom that serves the interests of neither the institution nor administrators. What you have to do is set up a schedule, let people know your schedule and that you will be your own master, and do the administrative job fully and effectively in its critical dimensions. So long as you do the job fully and effectively, and behave as a contributing, cooperative, and collegial colleague, you will be able to determine the rest of what you do, so long as it redounds well to the institution.

\section{Paper and Email Queves}

Upon entering an administrative post, you must take pains to avoid succumbing to paperholism in its traditional and high-tech versions. Institutional management is deciding and acting not shuffling, piling, and filing paper or scanning and responding to endless queues of email. Some administrators consider desks smothered in paper piles, file folders in and out of racks, stacks of small squares of telephone messages to be answered, and monitor screens filled 
with email to be evidence of a tough and demanding job or a status symbol. Don't join this crowd! Most of the paper and electronic exchanges are of minor or no value, and they create enough clutter to bury the important messages. The leaner the flow and storage of paper and electronic messages to and from your office, the greater will be your efficiency in your job and your sanity.

\section{The Land of the Timid}

During departmental faculty meetings, just about everyone has something to say; every faculty member is a rabbi, and, as the story goes, when you ask 10 rabbis their opinion you get 20 opinions. Such is not the case in a typical administrative meeting. Many administrators manifest a pervasive, observable, and dysfunctional unwillingness to express their views. They walk on eggs in their relations with the president or anyone one rung above them on the administrative ladder. For example, I frequently found myself in meetings at which the president or other administrator presiding because of rank tossed a provocative question or controversial issue on the table and asked for open and frank discussion ("Don't be bashful! Don't tell me what you think I want to hear!"), only to watch the cadre of administrators around the table sit mute or respond like lapdogs. Several never uttered a word, regardless of the frequency of the meetings or the criticality of the issues or the times. They would not tell the president or whoever that he or she was in error or off the mark, that the logic of his or her argument was flawed, that the conclusion lacked factual support, that the document might be better written, that the approach was impolitic and with unintended and dangerous conse- quences, or that there might have been another and possibly more productive way to look at the issue.

What should you do in such situations? Boldly but politely take the presiding officer at his or her word, and say what you have to say in a direct, professional, and civil way. To be sure, you may find yourself without declared allies. On several occasions, at a break in the meeting colleagues crowded at the coffee urn or muffin platter would mumble in undertones to me that they agreed with me or they thanked me for my statement, only to remain mute and unsupportive once we returned to the conference table.

I also should note in fairness and in your interest that the president or other muckymucks may tell you that they want to hear open debate and contrary views in their councils when they really do not want to hear dissent. The toadies who nod agreement or keep their mouths shut may enhance their job security, but they usually do so at the expense of what is best for the institution. It certainly will not do your self-esteem or your blood pressure any good to remain silent when given a chance to speak against a bad policy. When accepting administrative posts, you must take the measure of those you will work for and with, listen to their words but also judge their underlying characters, and then determine the parameters of your own behavior. My advice is to act confidently and state your mind when you have thought the matter through and you are comfortable with your argument, and when you think it is an issue important to the well-being of the institution. Life is too short and sychophantism too humiliating to do otherwise. If you are valuable in your job, you will have little to fear from speaking your mind. If there is something to fear, then probably you do not want to continue in administration anyway and you can always return to your faculty home.

\section{A Final Plea}

I have laid before you some of the major plusses and minuses of serving as a university administrator, and I have offered some advice on negotiating an administrative assignment and navigating its waters. Able academics cannot and should not abdicate the administering of their universities and colleges to others. The best and the brightest in the academic community should consider serving in administrative posts at appropriate points in their careers and the life of the institution. Indeed, I would argue that administrating is a professional obligation, especially for political scientists who value and urge involvement in the larger community. Certainly, a central theme of political science as it prepares to celebrate its centennial is education for citizenship and leadership in public service. Holding academic administrative offices offers political science faculty members the chance to meet that challenge.

While I have argued against viewing administration as a long-term career, that is a matter for individual decision. The choice rests on your circumstances and that of your institution, the challenges (or tedium) of available positions, how addicted you are to your discipline and inquiring and teaching about it, and your personal and professional goals. Regardless, an administrative tour of duty or two or three, at stages of your career, offers you the opportunity to test, to grow, to make a contribution, and to enjoy.

\section{Note}

* Special thanks are owed to Harry D. Boonin, Marilyn E. Throne, Miriam B.
Waltzer, and James R. Woodworth for their helpful comments and suggestions. Responsi- bility for the contents of the essay sits solely with the author. 